Maze preferences in naive rats produced by injection of ribonucleic acid from trained rats: $A$ further comment

by A. G. Worthington and M. B. Macmillan

Jacobson et al (1966) claim to produce evidence suggesting an RNA transfer effect in connection with maze preference behavior. In view of the sophisticated and time consuming biochemical procedures required in studies of this type it is to be regretted that on methodological grounds the conclusions reached are untenable.

The rationale for the training of the first group of animals is not clear. After indicating that these animals showed no preference the authors then say that they trained the animals to the side opposite to their initial preference., Some inconsistency is apparent here. Further, the authors give no reason why three of the original eight rats given the preference test took no further part in the experiment.

The statistical treatment of the results is based upon the assumption that one experimental treatment onl y was used whereas actually ten non-independent treatments were used. The number of treatments is given by the use of six groups of five rats and four groups of three rats; the non-independence occurs as a consequence of the donor-recipient sequence used. Such a sequence necessitates the use of a large number of control groups with and without injections of RNA from untrained donors. This condition was partly met by the authors in an earlier paper (Babich et al, 1965).

The statistical treatment, even if legitimate, is also open to criticism as Barker (1966) has already pointed out. To this we would add that the categorization procedures used by Jacobson et al in the preparation of their Table 1 increase the probability of a Type 1 error.

\section{References}

Babich, F. R., Jacobson, A. L., Bubash, S., \& Jacobson, Ann Transfer of a response to naive rats by injection of ribonucleic acid extracted from trained rats. Science, 1965, 149, 656-657. Barker, D. J. Comment on Jacobson et al. Psychon. Sci., 1966 , 4,314 .

Jacobson, A. L., Babich, F .R., Bubash, S., \& Goren, C. Maze preferences in naive rats produced by injection of ribenucleic acid from trained rats. Psychon. Sci., 1966, 4, 3-4.

\title{
Reply to comment by Worthington and Macmillan
}

by Allan L. Jacobson

Worthington and Macmillan obviously misunderstood what we consider a rather direct explanation about the preference-testing of the first eight rats in our experiment. Each rat was given 11 trials, on the basis of which a "preference" was arbitrarily defined. Clearly, each rat necessarily exhibited a preference, as defined, since each rat necessarily chose one alternative more frequently than the other. What is not so clear is how Worthington and Macmillan inferred that we indicated the first group of animals "showed no preference." The statement we made was the following: "Preference trials for the first eight rats showed that alternatives $\mathrm{A}$ and $\mathrm{B}$ were chosen equally (44 choices of each) and that individual biases tended to be small." Each rat was then trained to the side it chose less frequently on preference trials. I think Worthington and Macmillan's misunderstanding is apparent without further elaboration.
Three rats, randomly selected, were discarded initially, because we did not have enough time at that point to train all eight.

With reference to Worthington and Macmillan's third point: the design of our experiment was not so neat as it would have been had we used new animals for each successive run. Since the recipient for one run became a donor the next run, one might argue that the independent variable is complex. Nonetheless, it is important to note that a recipient was trained to the same side as that to which its respective donor had been trained-i.e., the two effects were consistent. Thus, while the independent variable may be complex, any systematic biases in recipient animals are attributable to training of donor animals. I can thus agree with Worthington and Macmillan about the desirability of using new animals but not with their interpretation of the design we did use. 